\title{
Wear and Corrosion Behavior of Tungsten Carbide Based Coating on Carbon Steel
}

\author{
Noor Aqilah Ahmad ${ }^{1}$, Zakiah Kamdi ${ }^{*}$, Abdul Latif Mohd Tobi
}

Faculty of Mechanical and Manufacturing Engineering, Universiti Tun Hussein Onn Malaysia, 86400, Batu Pahat, Malaysia.

Received 26 January 2018; accepted 5 August 2018, available online 5 August 2018

\begin{abstract}
High velocity oxy-fuel (HVOF) coating techniques are employed mainly to improve the service life of engineering components, which is exposed to wear, erosion, corrosion or combination of both; wear and corrosion. The aim of this study is to investigate the wear and corrosion behavior of tungsten carbide $10 \mathrm{wt} . \% \mathrm{nickel}$ (WC-10Ni) and tungsten carbide $12 \mathrm{wt} \% \mathrm{w}$ cobalt (WC-12Co) coating deposited onto medium carbon steel (Cast steel BS 3100 GR A3) blade. The blade was used to stir the mixture of sulfuric acid $\left(\mathrm{H}_{2} \mathrm{SO}_{4}\right)$ with ilmenite to produce titanium dioxide $\left(\mathrm{TiO}_{2}\right)$ pigments. The microstructures of both coatings before and after wear and corrosion testing were evaluated by using scanning electron microscope (SEM). Vickers microhardness testing was used to examine the coatings hardness. The three-body wear test with wet condition using silicon carbide (SiC) slurry was used to investigate the wear behavior for both coating. The experiment was based on weight loss of the sample and Archard's law to determine the wear rate of the coating. In addition, the three-electrode electrochemical test was used to investigate the corrosion behavior of the coatings. The mixture of $\mathrm{H}_{2} \mathrm{SO}_{4}$ and ilmenite used as an electrolyte of the test. It is found that the wear rate will increase with increasing of the weight loss. This is consistent with decreases of the volume fraction loss and hardness of the coating. After corrosion test, it can be observed that the existence of the crack and porosity on the coating increasing the corrosion behavior of coating. With high volume fraction and hardness, WC-12Co shows higher wear resistance compared to WC-10Ni. However, the value of corrosion rate for both coating has a slight difference due to better corrosion resistance of $\mathrm{Ni}$ binder itself.
\end{abstract}

Keywords: HVOF, WC-10Ni, WC-12Co, Wear, Corrosion

\section{Introduction}

Nowadays, weld hardfacing has been evolved rapidly and applied in various industries including nuclear, steam power plants, agriculture and railways, and even in aerospace components [1] . This process not only capable to reduce the cost but also hold promise in improving the life service of machine parts by fabricating or rebuilding [2] . However, these hardfacing techniques also brings along together some crucial problems such as wear, erosion and corrosion which relating to some application of hardfacing material and its composition of the chemical for a certain application [3].

Most industries face the biggest problem of wear and corrosion, which occur due to several factors such as exposure, strain and weakness during manufacturing process. Therefore, the components need replacement which cost money and downtime of the equipment. Researchers have identified that by replacing the component frequently, it has caused the working parameters of facility disorganized, productivity decreased and the energy consumption increased [4]. Moreover, wear and corrosion often combine to cause aggressive damage in a number of industries [5].

Thus, another method, high velocity oxy fuel (HVOF) thermal spray has been introduced to enhance the wear and corrosion resistance. HVOF is widely used in groups of thermal spraying and it has been extensively used for WC feedstock powder in order to obtain good bond strength, higher density and less decarburization. This is due to the lower temperature $\left(3000{ }^{\circ} \mathrm{C}\right)$ and higher velocities $(400 \mathrm{~m} / \mathrm{s}-1000 \mathrm{~m} / \mathrm{s})$ experienced by the powder particles as compare to other thermal spray technique like vacuum/low pressure plasma (VPS/LPPS), and atmospheric plasma (APS) with temperature around $12000{ }^{\circ} \mathrm{C}$ with $150 \mathrm{~m} / \mathrm{s}-600 \mathrm{~m} / \mathrm{s}$ velocities [6]. In order to achieve higher wear and corrosion resistance, adhesion and porosity of the coating are important properties. Thus, HVOF method is preferred for producing coating with high adhesion and low pores. The main feature of the HVOF method is its ability to produce dense coatings 
with small amount of degradation, oxidation of materials, and transformations of the phase due to short dwell time of the particles in a relatively cold flame [7].

This thermal sprayed technique is widely used to deposit tungsten carbide-based cermets (WC-based), metals and alloys coatings such as WC-Ni, WC-Co and $\mathrm{WC}-\mathrm{CoCr}$ to restrain the components from corrosion and wear in most industries such as aerospace, petroleum and steel metallurgy [7]. As a based material, WC has been thought of as one of the key factors in controlling wear and corrosion resistance, where content, size and distribution of the WC particles take decisive influence on the wear characteristics. Previous study has reported the wear resistance increases with rising of WC content and reducing the carbide particle size of the powder [8]. Over the years, WC have also proven their superiority in great number of other tooling and engineering applications compared to the other carbide due to their properties including high hardness, great abrasion or wear resistance, high modulus of elasticity, high compressive strength and low thermal expansion [8].

Moreover, cemented tungsten carbide has been introduced to improve the performance of the $\mathrm{WC}$, where it consists of the hard carbide (WC) phase embedded in a ductile metallic matrix, referred to the binder phase such as Cobalt (Co) and Nickel (Ni). For this carbide, components properties are superimposed where the carbide phase produces high hardness and wear resistance. Meanwhile, the binder with ductile feature contributes to toughness and strength. It is often referred as hard metals for excellent combination of hardness and toughness [9] .

This study is thus aimed at enhancing wear and corrosion resistance using HVOF thermal spray coating. The use of HVOF spray is seen extensively for improving components life due to excellent wear and corrosion resistance. In this research, $\mathrm{WC}-10 \mathrm{Ni}$ and $\mathrm{WC}-12 \mathrm{Co}$ coatings were deposited onto mild steel specimens. The coating characterization was studied using scanning electron microscope (SEM) before and after wear and corrosion test. Coating was tested using Vickers microhardness and surface roughness of the coating after wear also determined. Three-body wear test was carried out under wet condition with silicon carbide (SiC) slurry using modified grinder machine. While, electrochemical test was used to run the corrosion test, which was the sample act as working electrode, platinum $(\mathrm{Pt})$ wire gauze as counter electrode and sliver/silver chloride $(\mathrm{Ag} / \mathrm{AgCl})$ used as a reference electrode. Electrolyte solution that used in this study was combination of $\mathrm{H}_{2} \mathrm{SO}_{4}$ and ilmenite. The effect of microstructure, phase composition and hardness on wear and corrosion had been studied.

\section{Materials \& Methods}

\subsection{Coating Deposition}

The material selection is very important due to its benefit and limitation. In this research, the powder used in the present work are $\mathrm{WC}-10 \mathrm{Ni}$ and WC-12Co. The powder was deposited by the $\mathrm{HVOF}$ technique onto medium carbon steel (Cast steel BS 3100 GR A3) blade with dimension of $955 \mathrm{~mm}$ x $370 \mathrm{~mm}$ x $25 \mathrm{~mm}$. Before coating deposition, the blade underwent the grit blasting process by using aluminium oxide. Grit blasting has always been considered as a conventional process, which is also known as sand blasting. It is a vital process, where it is not only done to remove rust, but to prepare the surfaces for high performance coatings or to treat final products to give them the luster and desired surface texture. Besides, the other purpose of this process is to make sure the spray powder (coating) strongly bonds to the substrate. The Diamond Jet (SULZER METCO) was used to spray the powder at very high speed $(700 \mathrm{~m} / \mathrm{s})$ with low temperature at $900{ }^{\circ} \mathrm{C}$ resulting a hard dense and porous-free coating characteristics. While, the parameter of machine was set based on the type of powder used as shown in Table 1. Both coating subsequently deposited with average thickness from $200 \mu \mathrm{m}$ to $300 \mu \mathrm{m}$.

Table 1: Deposition parameters for both coating.

\begin{tabular}{|c|c|c|}
\hline & WC-10Ni & WC-12Co \\
\hline $\begin{array}{lll}\text { Powder } & \text { feeding } & \text { rate } \\
(\mathrm{SCEH}) & & \end{array}$ & 28.5 & 28.5 \\
\hline Particles size $(\mu \mathrm{m})$ & $45 \pm 11$ & $45 \pm 5$ \\
\hline Oxygen Pressure (psig) & 150 & 150 \\
\hline Fuel Pressure (psig) & 110 & 110 \\
\hline Air Pressure (psig) & 100 & 105 \\
\hline Air flow (SCEH) & 893 & 730 \\
\hline Fuel flux (SCEH) & 432 & 461 \\
\hline Oxygen flux (SCEH) & 635 & 433 \\
\hline Spraying distance (in.) & 9 & 10 \\
\hline Spray Rate (lbs/h) & 5 & $5-10$ \\
\hline
\end{tabular}

\subsection{Coating Characterization and Micro- Hardness Tester}

After the coating process, the blade was cut into small pieces $(10 \mathrm{~mm}$ x $10 \mathrm{~mm}$ x $15 \mathrm{~mm}$ ) using EDM wirecut. Then, the sample was ground using sand paper with 360 to 1500 grit before polishing with additional of alumina $0.05 \mu \mathrm{m}$. The surface morphology of the coating is carried out using scanning electron microscope (SEM, Jeol 2000).

Microhardness of the coating was taken using Vickers Micro-Hardness (Shimadzu, Japan) fitted with diamond indenter. A load of $490.3 \mathrm{mN}(0.05 \mathrm{HV})$ was 
applied within $10 \mathrm{~s}$ dwell time. The test was carried out in homogeneous and free of pores zones. An average of 10 microhardness values was acquired from the tester.

\subsection{Sliding Wear \& Electrochemical Test}

The sliding wear test was conducted by using modified METKON grinder and polishing machine with the distance of $1000 \mathrm{~m}, 2000 \mathrm{~m}, 3000 \mathrm{~m}$ and $4000 \mathrm{~m}$. Before the test, the sample was mounted so that it fitted to the holder of the machine with $20 \mathrm{~N}$ applied force. The speed used for the wear track was $200 \mathrm{rpm}$ as well as the pump speed that supplied silicon carbide ( $\mathrm{SiC}$ ) slurry. $\mathrm{SiC}$ was chosen due to the high hardness according to Mohr's hardness compared to other slurry as well as its appropriateness for abrasive wear test.

The wear test was carried out to determine the amounts of removal material (the coating) that worn after the test. The weight loss technique was used in this test, where the sample was weighed before and after the wear. In this investigation, Archard's law was used to determine the wear rate that relates to the volume of material removed. In Archard's equation, it asserts that the wear volume, $\mathrm{v}$ is directly proportional to the force or load, $\mathrm{P}$ on the contact and sliding distance, s but inversely proportional to the surface hardness, $\mathrm{H}$ of the material [10] as shown in equation 1. Surface roughness of the coating after wear is measured using profilometer (Mitutoyo SJ400, Japan).

$$
v=K \times \frac{P s}{H}
$$

- $\quad v=$ volume of material removal $\left(\mathrm{mm}^{3}\right)$

- $K=$ dimensionless wear coefficient/ wear rate $\left(\mathrm{mm}^{3} / \mathrm{Nm}\right)$

- $\quad P=\operatorname{load}(\mathrm{N})$

- $\quad s=$ sliding distance $(\mathrm{m})$

- $H=$ Hardness of material

In this study, the electrochemical test was used to evaluate the corrosion behavior of both coating and the sample would act as the working electrode. While, platinum $(\mathrm{Pt})$ wire gauze was used as counter electrode and silver/ silver chloride $(\mathrm{Ag} / \mathrm{AgCl})$ as a reference electrode that connected to lugging capillary. The combination of $1.0 \mathrm{M}$ concentration of sulfuric acid $\left(\mathrm{H}_{2} \mathrm{SO}_{4}\right)$ and $1.35 \mathrm{~g}$ ilmenite was used as electrolyte with voltage range from $-0.25 \mathrm{~V}$ to $0.25 \mathrm{~V}$. Tafel curve was made for both coating respectively. Tafel slope constants associated with anodic $\left(\mathrm{B}_{\mathrm{a}}\right)$ and cathodic $\left(\mathrm{B}_{\mathrm{c}}\right)$ processes, $\mathrm{E}_{\text {corr }}$ (corrosion potential) and $\mathrm{I}_{\text {corr }}$ (corrosion current density).

\section{Results \& Discussion}

\subsection{Microstructure Analysis}

Surface morphology of the backscattered electron (BSE) for both coatings are shown in Fig. 1 and Fig. 2. Characterizations of the carbide phase and $\mathrm{Ni} / \mathrm{Co}$ matrix morphology revealed a similar distribution of reinforced carbide particles in the metal matrix. The visible carbide grain size for $\mathrm{WC}-12 \mathrm{Co}$ is finer that is in average $2.3 \mu \mathrm{m}$ than WC-10Ni $(2.7 \mu \mathrm{m})$. The result showed that the carbide phase volume fraction for the $\mathrm{WC}-10 \mathrm{Ni}$ is $77 \%$ with $0.47 \mu \mathrm{m}$ mean free path. While, WC-12Co has higher volume fraction that is $87 \%$ with low mean free path $(0.23 \mu \mathrm{m})$. The wear performance depends on its microstructure and the volume fraction of carbides, in which the coatings that have higher volume fraction will perform better wear resistance [11]. Moreover, the coatings with higher mean free path distances between the reinforcing WC particles have higher wear rates [12].

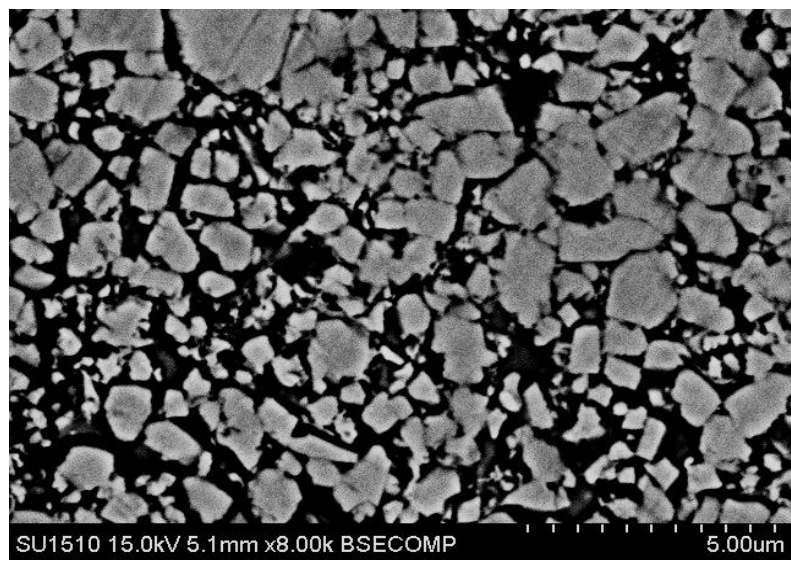

Fig. 1: Microstructure of WC-10Ni coating.

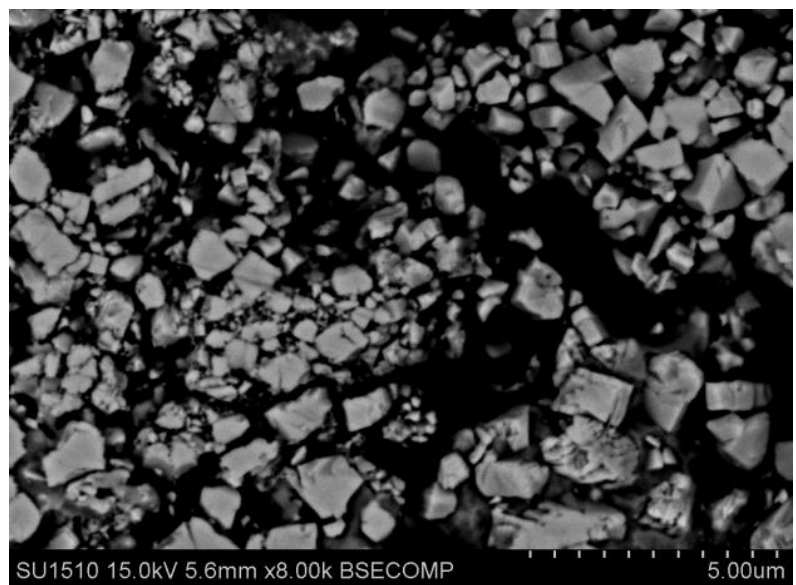

Fig. 2: Microstructure of WC-12Co coating.

It has been observed the distribution of tungsten carbide (WC) consists of angular shape, which is in light contrast dissolve into metallic binder of $\mathrm{Co}$ and $\mathrm{Ni}$, which is in dark contrast. WC is preferentially melted into the both binder phases in high temperature during thermal 
spray process [13]. Pores which have been formed during deposition process within the coatings have an effect on some of mechanical properties such as elastic modulus, shear modulus and hardness that may affect the wear performance [14].

\subsection{Wear Analysis}

From the results obtained, the wear volume plotted against sliding distance showed that the wear volume increases with the increasing of the sliding distance due to the loss of the carbide phase. It shows that, the weight loss of the WC-10Ni is higher compared to WC-12 Co, which leads to higher wear volume as shown in Fig. 3. The behavior of both materials can be divided into two regions, where the first region is the non-steady state (from $0 \mathrm{~m}$ to $2000 \mathrm{~m}$ ) in which the interaction between the two surfaces is initiated. The second stage is the steady state (from $2000 \mathrm{~m}$ to $4000 \mathrm{~m}$ ) where the carbide and the stainless steel surfaces are in intimate contact. The stability of the weight loss is recorded after the 2000 $\mathrm{m}$ sliding distance due to the reduction in friction of the new surface qualities [15].

The average wear rate of the $\mathrm{WC}-12 \mathrm{Co}$ is lower that is $0.0062 \mathrm{~mm}^{3} / \mathrm{Nm}$ compared to WC-10Ni that has higher wear rate $\left(0.0124 \mathrm{~mm}^{3} / \mathrm{Nm}\right)$. It can be correlated with the Archard's law, where the wear rate increases with the increasing of the wear volume.

This can be explained by the hardness of the coating, where the increasing of the hardness of the coating producing lower wear rate as shown in Fig. 4. Additionally, the spraying of the coating with poorer adhesion between the coating and substrate, again resulting in high rates of wear [16].

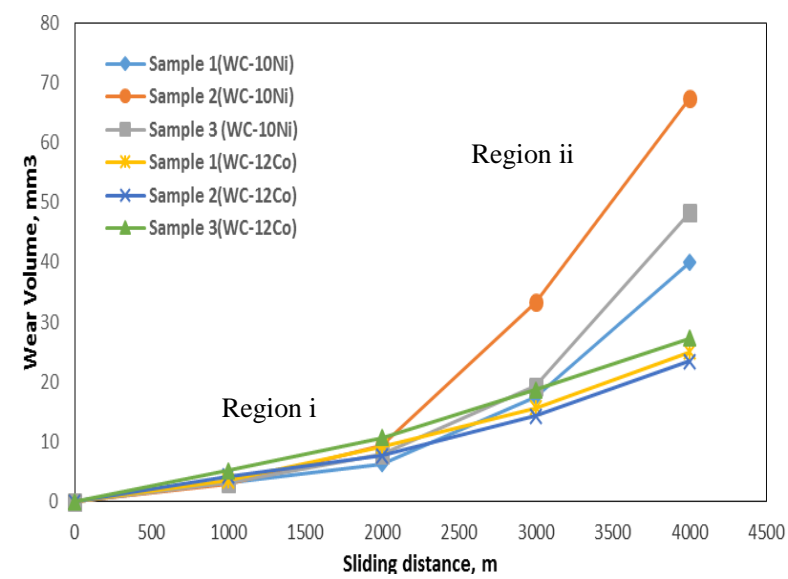

Fig. 3: Wear volume against sliding distance.

Fig. 5 depicts the worn surface of WC-10Ni after the wear test up to $4000 \mathrm{~m}$ sliding distance. The abrasive wear is determined on the surface of the coating from the SEM micrograph. With the increasing of the sliding wear conditions, wear trace of each sample becomes bigger which indicating the loss of the carbide and binder particles. The wear trace of WC-12Co coating is shallow as proved by surface roughness measurement compared to WC-10Ni as illustrated in Fig. 5 and Fig. 6. The average surface roughness for the $\mathrm{WC}-12 \mathrm{Co}$ is $3.36 \mu \mathrm{m}$ compared than $\mathrm{WC}-10 \mathrm{Ni}(4.14 \mu \mathrm{m})$. The roughness value was measured with the direction of the sliding. It also shows that, there is no more $\mathrm{WC}-10 \mathrm{Ni}$ coating on the substrate after $4000 \mathrm{~m}$, compared to $\mathrm{WC}-12 \mathrm{Co}$, where it still has some coating on the substrate.

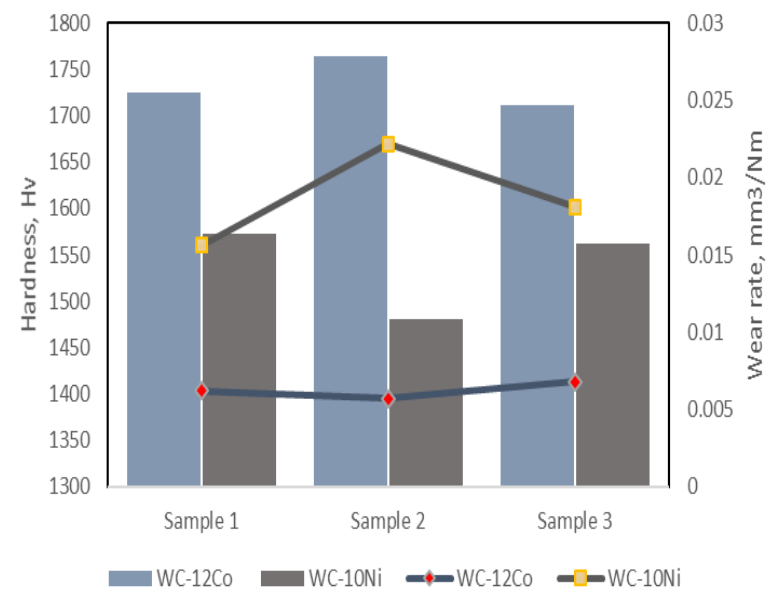

Fig. 4: Wear rate against hardness of the coating.

Grooving along the sliding direction is clearly seen for both coatings. This is indicator of typical abrasion wear, encountered when an abrasive $\mathrm{SiC}$ is sliding against an elastoplastic metallic surface (WC-10Ni and WC12 Co coating). No crack was detected on the surface, where this was associated with the elevated bonding strength between the substrate and coating as well as the significant role that bond strength can play in splat propagation and resistance to crack initiation [17]. In addition, wide and deep grooves were created on the surface at the $4000 \mathrm{~m}$ sliding distance, where resulted the loss of carbide.

An improvement in the matrix alloy hardness and the bonding strength between the carbide and the matrix could enhance the abrasive wear resistance of the coating. Moreover, abrasive particles ( $\mathrm{SiC}$ ) also influenced the wear rate of coatings. Kamdi et al. [18] has found that the matrix phase is protected by WC phases when the abrasive particles of are the same scale or larger than the mean free path between hard phases. With large scales of SiC particles $(200 \mu \mathrm{m}-400 \mu \mathrm{m})$, cobalt binder phase is protected from contact with the abrasive by the smaller mean free path between carbide phases, resulting in low wear rate of the WC-12Co coating. Wear rate is very sensitive to abrasive characteristics such as chemical composition, shape, size and angularly [17]. For example, 
the abrasive particle shape can have significant influence on the wear mechanism. As reported by other researchers, abrasive particles with an angular shape can generate wear rates higher than the rounded ones. Since finer rounded particles produce less damage on the surface, the coating would show a lower wear rate [19][20]. Therefore, finer grain size with high volume fraction and lower mean free path, as well as high hardness leads to the excellent wear rates of WC-12Co coating.
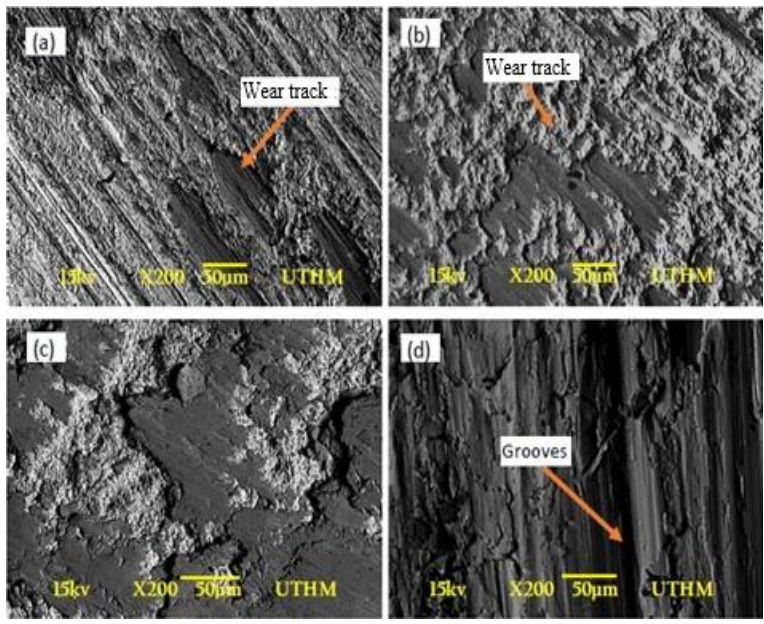

Fig. 5: Wear surface of WC-10Ni coating; (a) 1000 m; (b) $2000 \mathrm{~m}$; (c) $3000 \mathrm{~m}$; (d) $4000 \mathrm{~m}$.
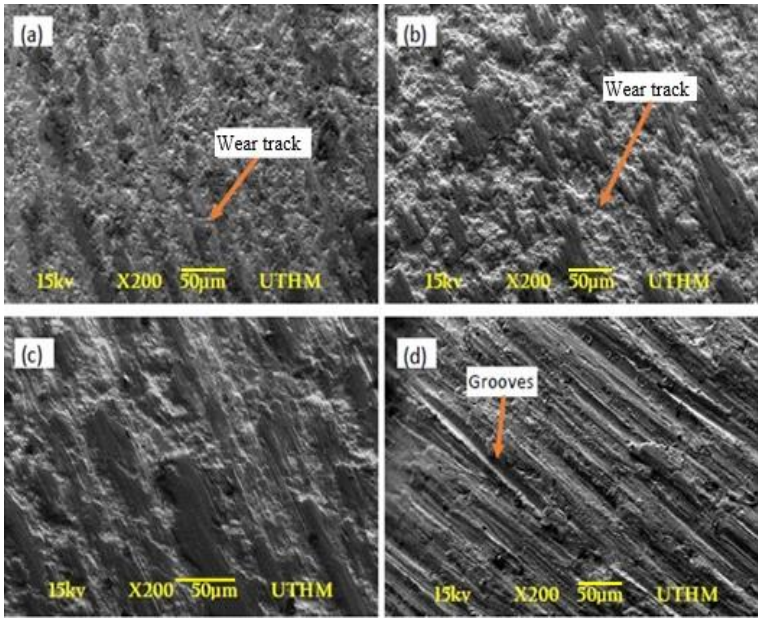

Fig. 6: Wear surface of WC-12Co coating; (a) $1000 \mathrm{~m}$; (b) $2000 \mathrm{~m}$; (c) $3000 \mathrm{~m}$; (d) $4000 \mathrm{~m}$.

\subsection{Electrochemical Analysis}

The polarization curves were fitted in order to determine the electrochemical parameters and the results are tabulated in Table 2. It can be observed on Fig.7, WC$10 \mathrm{Ni}$ coating exhibits better corrosion resistance indicated by the lower passive current density, $I_{\text {corr }}$ and wide passive region due to denser coating, reduced porosity and micro-cracks [21] and better corrosion resistance of the $\mathrm{Ni}$ binder [22]. Similar observations have been reported by Kalish [23] for bulk WC-Ni composites and attributed to the corrosion resistant nature of the $\mathrm{Ni}$ binder. Moreover, the open circuit potential (OCP) of the sample coated with WC-10Ni also shows more noble than other coating. These outcomes suggest that the carbon steel coated with WC-10Ni offers good protection of the blade substrate against corrosion.

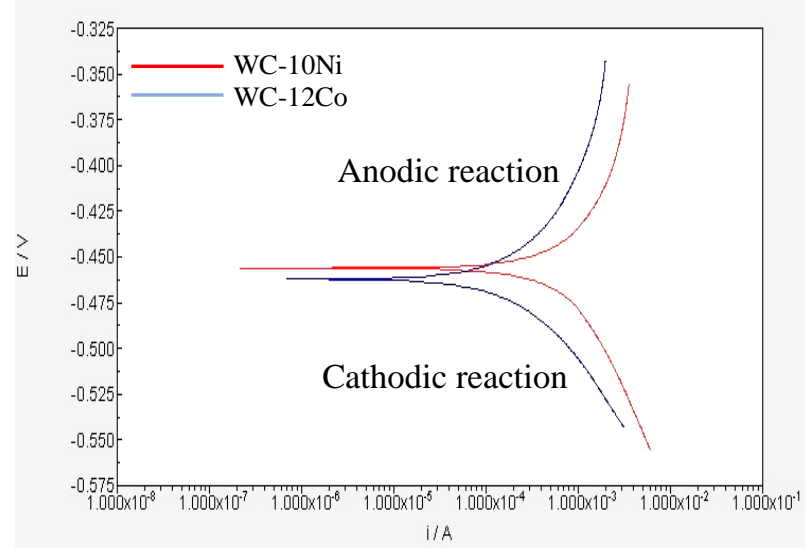

Fig. 7: Tafel graph for WC-10Ni and WC-12Co coating.

Table 2: Tafel curve data for WC-10Ni and WC-12Co coating.

\begin{tabular}{l|cc}
\hline Results & $W C-10 N i$ & $W C-12 C o$ \\
\hline $\mathrm{E}_{\mathrm{corr}}[\mathrm{V}]$ & -391.000 & -404.000 \\
$\mathrm{I}_{\mathrm{corr}}[\mathrm{A}]$ & $1.905 \times 10^{-4}$ & $5.105 \times 10^{-4}$ \\
$\mathrm{~B}_{\mathrm{a}}$ & 0.102 & 0.026 \\
$\mathrm{~B}_{\mathrm{c}}$ & 0.046 & 0.056 \\
$\mathrm{R}_{\mathrm{p}}$ & 9.845 & 7.479 \\
Corrosion Rate, $\mathrm{C}_{\mathrm{R}}$ & 1.221 & 1.922 \\
{$[\mathrm{~mm} / \mathrm{y}]$} & & \\
\hline
\end{tabular}

A scanning electron micrograph of the corroded WC$10 \mathrm{Ni}$ and WC-12Co coating surface is shown in Fig. 8 and Fig. 9 respectively. The formation of large voids in both coating attributed to mechanical and chemical effects, whereby (i) dissolution of soluble phases within the coating and/or (ii) erosion of certain phases within the coating may have occurred [22].

According to corrosion mechanisms, the voids/ holes from pull out of the WC cannot be avoided in WC-based cermet coatings during electrochemical corrosion process. This is attributed to high level of porosity and cracks in the coating, resulting in attack of the substrate directly by acidic solution [16].

Potentiodynamic curves revealed poor corrosion performance of the $\mathrm{WC}-12 \mathrm{Co}$ coating when compared with the WC-10Ni. With the increased of $\mathrm{I}_{\text {corr }}$ values and more negative $\mathrm{E}_{\text {corr }}$ attributed to the poor structure and possible galvanic coupling effect between cobalt and the WC hard phase [24]. It is mainly related to the leaching 
of cobalt which serves as the anode (WC as cathode) in micro-galvanic corrosion. It has been acknowledged that the micro-galvanic corrosion markedly exacerbates the cobalt oxidation by the electron acceptors (i.e. oxygen) in acidic media, which can occur in the area ratio effect between large cathode (WC phase) and small anode (binder phase). Moreover, the high levels of porosity in the coating influence the corrosion performance, resulting in attack of the substrate directly by the saline environment. This is possibly due to the incomplete sintering between the WC matrix and the binders during the HVOF thermal spraying process [22].

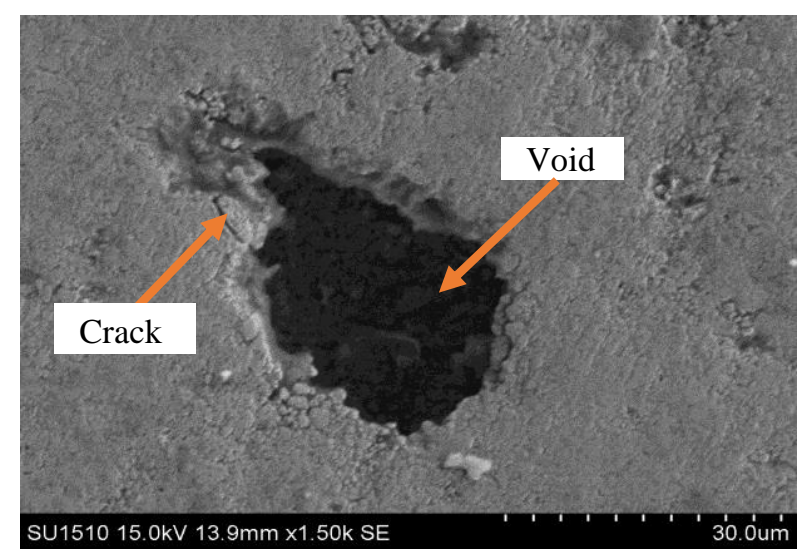

Fig. 8: Surface micrograph after corrosion test of WC$10 \mathrm{Ni}$ coating.

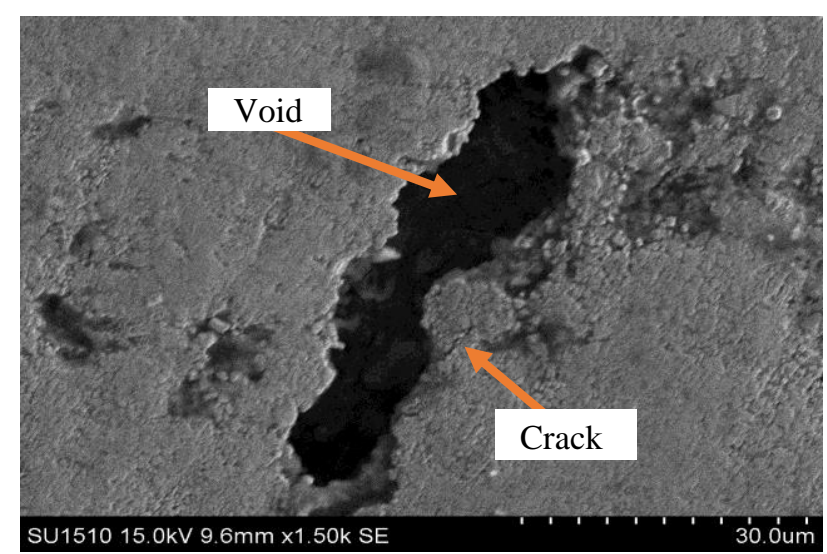

Fig. 9: Surface micrograph after corrosion of $\mathrm{WC}-12 \mathrm{Co}$ coating

\section{Summary}

In the present work, surface morphology revealed that both coatings have angular shape of carbide and WC grains preferentially melted into binder phase of $\mathrm{Ni}$ and Co. However, WC-12Co has finer grain size that is 2.3 $\mu \mathrm{m}$ compared to $\mathrm{WC}-10 \mathrm{Ni}(2.7 \mu \mathrm{m})$. Moreover, WC$12 \mathrm{Co}$ has high volume fraction with low mean free path which resulting in high wear resistance of the coating. However, inevitable pores and cracks are likely to be possessed due to high velocity impact of both coating materials to the substrate.
From the result, it can be concluded that the wear rate of the $\mathrm{WC}-12 \mathrm{Co}$ is widely lower than $\mathrm{WC}-10 \mathrm{Ni}$. This is due to the properties of the combination $\mathrm{WC}$ and $\mathrm{Co}$ in producing high hardness, which is around $1700 \mathrm{Hv}$ compared to WC-10Ni $(1500 \mathrm{Hv})$. The formation of deep groove and micro-ploughing for both coatings is indicated when an abrasive $\mathrm{SiC}$ is sliding against metallic surface. Moreover, no crack detected on the surface due to the high bonding strength between the substrate and coating.

For the corrosion, it revealed that WC-10Ni coating exhibits better corrosion resistance with lower passive current density, $\mathrm{I}_{\text {corr. }}$. This can be explained by the denser coating, low porosity and better corrosion resistance of the Ni binder. WC-12Co has good corrosion resistance, where the difference of corrosion rate for both coatings is only $0.7016 \mathrm{~mm} / \mathrm{y}$. As for both coatings, they show the formation of large voids caused by mechanical and chemical effect, where dissolution of soluble phases within the coating and erosion of certain phases within the coating has occurred. Moreover, low corrosion resistance of $\mathrm{WC}-12 \mathrm{Co}$ is due to the preferential cobalt loss caused by the galvanic coupling effect in acidic environment.

\section{Acknowledgement}

The authors gratefully acknowledge this research which was financially supported by Knowledge Transfer Programmed (KTP) project under grand no 1483.

\section{References}

[1] Kirchgaßner, M., Badisch, E. and Franek, F. Behaviour of iron-based hardfacing alloys under abrasion and impact. Wear, Vol. 265, (2008), pp. 772-779.

[2] Pradeep, G.R.C., Ramesh, A. and Kirchgaßner, M., Badisch, E. and Franek, F. Behaviour of ironbased hardfacing alloys under abrasion and impact. Wear, Vol. 265, (2008), pp.772-779.

[3] Prasad,B.D. Comparative study of hardfacing of AISI 1020 steel by gas welding and tig welding processes. IOSR Journal of Engineering, Volume2, (2012), pp.18-22.

[4] Shibe, V. and Chawla, V. Enhancement in wear resistance by hardfacing: A review. Mechanica Confab, Vol. 2, (2013), pp. 111-122.

[5] Arsic, D., Lazic, V., Mutavdzic, M., Nikolic, R., Aleksandrovic, S., Mitrovic, S., and Dordevic, M. Experimental Investigation of wear resistance of models hard faced with various filler metals. International Conference on Tribology, Vol. 14, (2015), pp. 169-175.

[6] Davis, J.R. Introduction to thermal spray processing. Handbook of Thermal Spray Technology, (2004), pp. 3-13.

[7] López, A. J., and Rams, J. Protection of carbon steel against molten aluminum attack and high 
temperature corrosion using high velocity oxygenfuel WC-Co coatings. Surface and Coatings Technology, Vol. 262, (2015), pp.123-133.

[8] Oksa, M., Turunen, E., and Suhonen, T. Optimization and characterization of high velocity oxy-fuel sprayed coatings. Techniques, Materials, and Applications Coatings, Vol. 1, (2011), pp.1752.

[9] Woezel, M. Influence of thermal spraying method on the properties of tungsten carbide coatings. Thermal Spraying, (2003), pp.39-47.

[10] Su, W., Sun, Y., Liu, J., Feng, J., and Ruan, J. Effects of $\mathrm{Ni}$ on the microstructures and properties of $\mathrm{WC}-6 \mathrm{Co}$ cemented carbides fabricated by $\mathrm{WC}-$ 6(Co,Ni) composite powders. Ceramics International, Vol. 41(2), (2015), pp. 3169-3177.

[11] Williams, J. A. Wear modelling: analytical, computational and mapping: a continuum mechanics approach. Wear, Vol. 225, (1996), pp.1-17.

[12] Wang, Y.Y., Li, C.-J., Kusumoto, K. and Yang, G.-J. Deposition behaviors of solid phases in liquid-solid two-phase particles in high velocity oxy-fuel spraying. Materials Transaction, Vol. 47, (2006), pp. 1684-1689.

[13] Melendez, N. M., Narulkar, V. V, Fisher, G. A. and Mcdonald, A. G. Effect of reinforcing particles on the wear rate of low-pressure coldsprayed WC-based MMC coatings. Wear, Vol. 306, (2017), pp. 185-195.

[14] Gu, L., Huang, J., Tang, Y., Xie, C., and Gao, S. Influence of different post treatments on microstructure and properties of WC-Co cemented carbides. Journals of Alloys and Compounds, Vol. 620, (2015), pp. 116-119.

[15] Nahvi, S. M. and Jafari, M. Microstructural and mechanical properties of advanced HVOF-sprayed WC-based cermet coatings. Surface \& Coatings Technology, Vol. 286, (2016), pp.95-102.

[16] Sahraoui, T., Feraoun, H. I., Fenineche, N., Montavon, G., Aourag, H., and Coddet, C. HVOFsprayed tribaloy-400: Microstructure and first principle calculations. Material, Vol. 58, (2004), pp. 2433-2436.

[17] Oladijo, O. P., Obadele, B. A., Venter, A. M. \& Cornish, L. A. Investigating the effect of porosity on corrosion resistance and hardness of WC-Co coatings on metal substrates. Coatings, Vol. 2(1), (2016), pp. 37-45.

[18] Zavareh, M.A., Sarhan, A.A.D., Bushroa, A.R., and Basirun, W.J. The Tribological and electrochemical behavior of HVOF-sprayed
$\mathrm{Cr} 3 \mathrm{C} 2-\mathrm{NiCr}$ ceramic coating on carbon steel. Ceramics International, Vol. 41(4), (2015), pp. 5387-5396.

[19] Kamdi, Z., Shipway, P. H., Voisey, K. T., and Sturgeon, A. J. Abrasive wear behaviour of conventional and large-particle tungsten carbidebased cermet coatings as a function of abrasive size and type. Wear, Vol. 271(9-10), (2011), pp. 1264-1272.

[20] Wang, B.Q. and Shui, Z.R. The hot erosion behavior of HVOF chromium carbide-metal cermet coatings sprayed with different powders. Wear, Vol. 253, (2002), pp. 550-557.

[21] Scrivani, A., Lanelli, S., Rossi, A., Groppetti, R., Casadei, F., and Rizzi, G. A contribution to the surface analysis and characterisation of HVOF coatings for petrochemical application. Wear, Vol. 250, (2001), pp. 107-113.

[22] Hulka, I., Utu, D., Serban, V.A., Dan, M.L., Matikainen, V., and Vuoristo, P. Corrosion ebhavior of WC-Ni coatings deposited by different thermal spraying methods. Series of Chemistry and Environmental Engineering, (2015), pp. 6074.

[23] Ward, L.P., Hinton, B., Gerrad, D., and Short, K. Corrosion behaviour of modified HVOF sprayed WC based cermet coatings on stainless steel. Journal of Minerals \& Materials Characterization \& Engineering, Vol. 10(11), (2011), pp. 9891005.

[24] Kalish, H. S. Corrosion of cemented carbides, ASM Handbooks on-line, Vol.13B. (2009).

[25] Zhang, Q., He, Y., Wang, W., Lin, N., Wu, C., and $\mathrm{Li}, \mathrm{N}$. Corrosion behavior of WC-Co hardmetals in the oil-in-water emulsions containing sulfate reducing citrobacter. Corrosion Science, Vol. 94, (2015), pp. 48-60.

[26] Ebshish. A., Yaakob. Z., Narayanan. B., Bshish. A., and Wan Daud. W.R. The activity of Ni-based catalysts on steam reforming of glycerol for hydrogen production. International Journal of Integrated Engineering, Vol. 3, (2011), pp. 5-8.

[27] Hoa, N.K, Abd. Rahman., H., and Somalu.,M.R Influence of silver addition on the morphological and thermal characteristics of Nickel oxidesamarium doped ceria carbonate (NiO-SDCC) composite anode. International Journal of Integrated Engineering, Vol. 10, (2018), pp. 196201. 